\title{
Prevalence and classification of anatomical variations of mandibular canal in panoramic radiographies
}

George Borja de Freitas', Pierre Gomes de Morais Silva1, Jalber Almeida dos Santos, Luiz Roberto Coutinho Manhães Júnior², Paula Bernardon*

${ }^{1}$ Department of surgery, Integrated Patos College, Belo Horizonte, Patos, PB, Brazil, 2Department of radiology, St Leopoldo Mandic College, Preta, Campinas, SP, Brazil, ${ }^{3}$ Department of periodontology, Western Parana State University, Cascavel, PR, Brazil

\begin{abstract}
Introduction: Dental surgeries involving structures adjacent to the mandibular canal require greater knowledge of the intraosseous path, anatomical structure, and its variables, reducing the risk of injuries to this region. This research aimed to verify on the panoramic radiographs the anatomical characteristics of the mandibular canal, as well as to analyze and classify its pathways.

Methods: The classification of anatomical variations of the mandibular canal was divided into four types: Class A (inferior direction); Class B (mesial direction); Class C (alveolar direction); and Class D (retromolar direction). The sample consisted of 500 exams, 207 (41.4\%) males and 293 (58.6\%) females, with a mean age of 29.51 years.
\end{abstract}

Results: A prevalence of 30 anatomical variations of the mandibular canal was observed. The most prevalent classifications were Class B (43.6\%) followed by Class C $(23.1 \%)$ and D (33.3\%). In no case was the presence of bifid canals classified as Class $A$. The anatomical variations of the mandibular canal appeared both unilaterally and bilaterally, in which unilaterally the prevalence was on the left side $(50 \%)$, on the right side (20\%), and bilaterally (30\%).

Conclusions: According to the results obtained in this study, a prevalence of $6 \%$ of bifid mandibular canals was found. The most prevalent types of the bifid canal were Class B and Class D, and the highest occurrence of bifid mandibular canals was left unilateral. It is concluded that the appearance of mandibular canal anatomical variations in panoramic radiographs is frequent and that additional care must be taken to approach the region.

Keywords: Mandible; mandibular nerve; diagnostic imaging

\begin{abstract}
*Corresponding author: Paula Bernardon, Department of periodontology, Western Parana State University, University St., number. 1618, Cascavel, PR 85819-110 Brazil. Phone: +55 (45) 99914-8546. Fax: +55 (45) 3262-1677. ORCID: 0000-0002-28463950. E-mail: paula.bernardon@yahoo.com.br
\end{abstract}

Submitted: 10 February 2020/Accepted: 27 May 2020

DOI: https://doi.org/10.17532/jhsci.2020.888

UNIVERSITY OF SARAJEVO FACULTY OF HEALTH STUDIES

\section{INTRODUCTION}

The mandibular canal is located internally to the mandibular bone starting in the mandibular foramen in the lingual region, going through the mandibular angle and ending with its exteriorization, in the mental foramen, and may or may not continue its intraosseous path toward the mandibular 
region as a single canal. This canal obliquely crosses the entire mandibular body, becoming curved from posterior to anterior (1).

The radiographic aspect of the mandibular canal is characterized by a radiolucent band delimited by two radiopaque lines, usually as an odd structure, assuming different positions within the mandible body, both in the upper-lower and mid-lateral directions and may also present duplications or bifurcations in its path and, in some cases, trifurcations (2).

Anatomical variations of the mandibular canal may have different configurations and paths. Most of the time, the mandibular canal presents itself as a single conduit. However, in certain cases, the presence of an accessory canal can be identified and is called bifid. Although bifid mandibular canals are observed in a small portion of the population, detection of this type of anomaly is of fundamental importance for the correct planning of clinical and surgical interventions (3).

Dental surgeons are unaware of the anatomical variances of this canal and thus cannot visualize them in panoramic radiographs (4). The possibility of considerable variation in the path and number of canals makes it difficult to accurately visualize the mandible canal. The present study aimed to investigate the existence of anatomical variations of the mandibular canal in panoramic radiographs, as well as to correlate the types of anatomical variations in the mandibular canal with the sex and the affected side.

\section{METHODS}

The present study was observational, retrospective, epidemiological, and descriptive. The sample consisted of panoramic radiographic images of 500 patients that were selected from a total of 750 archival images from the Patos Image Clinic - PB Integrated College, according to the inclusion and exclusion criteria. The project was submitted and approved by the Research Ethics Committee with opinion number: 2.491 .239 according to resolution $196 / 96$ and the images were selected at random.

Samples of satisfactory quality of patients of both sexes over 18 years of age undergoing panoramic radiographs from 2014 to 2018 were included in the sample. Patients should have exclusively permanent dentition and the images should not have artifacts.
Patients with a history of mandible trauma, bone lesions in the lower arch and orthognathic, reparative surgery in the posterior region of the mandible, syndromic patients, or low-quality images were excluded from the sample.

To select panoramic X-ray acquisitions, all examinations were performed on the Orthophos XG Sirona ${ }^{\circledR}$ device. The factors used for acquisitions were those pre-established by the equipment that works with $86 \mathrm{kV}$ fixed and with $8 \mathrm{~mA}$ variation, according to the resolution.

Image selection was performed by chronological order using SIDEXIS XG panoramic radiographs software, to observe which have alterations in the mandible canal. In the data collection, an excel spreadsheet (Microsoft, Seattle, USA) was developed to record the selected exam number, identifying the presence of bifid mandibular canal, bifid canal type, affected side, age, and gender of the patient.

In cases where bifurcations occurred in the mandibular canal, based on Freitas et al. (2), a new classification was suggested that included all types of mandibular canal bifurcations visualized in panoramic radiographs, where these alterations were classified into four distinct classes: A, B, C, and $\mathrm{D}$ classes (Table 1 and Figures 1-4), according to the path of the bifid canal, taking as reference the beginning of the mandibular canal in the mandible foramen.

The standardization process for classifying mandibular canal bifurcation types, according to Freitas et al. (2), was performed by a single examiner with experience in the area. Thus, the examiner evaluated 20 panoramic X-rays randomly selected; after 30 days, a new evaluation of the images was performed to verify the intra-examiner agreement.

TABLE 1. Bifid mandibular canals classification

\begin{tabular}{ll}
\hline Class A & $\begin{array}{l}\text { Lower direction - Direction of the bifid MC toward } \\
\text { the lower face of the mandibular }\end{array}$ \\
Class B & $\begin{array}{l}\text { Mesial direction - MC bifid direction to mesial or } \\
\text { anterior }\end{array}$ \\
Class C & $\begin{array}{l}\text { Alveolar direction - Bifid MC direction to alveolar } \\
\text { or higher }\end{array}$ \\
Class D & $\begin{array}{l}\text { Retromolar direction - MC bifid direction for } \\
\text { retromolar region }\end{array}$ \\
\hline
\end{tabular}

${ }^{*} \mathrm{MC}$ : Mandibular canal 


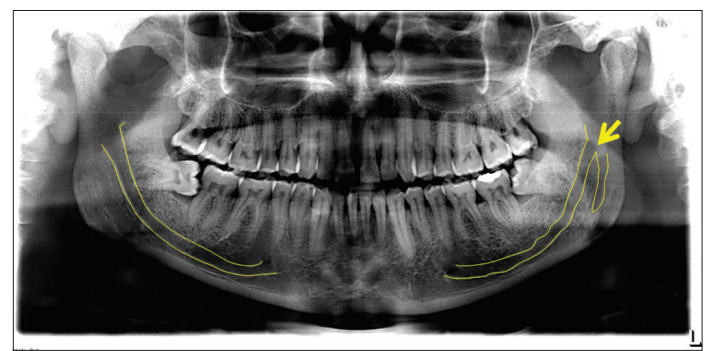

FIGURE 1. Class A-lower direction.

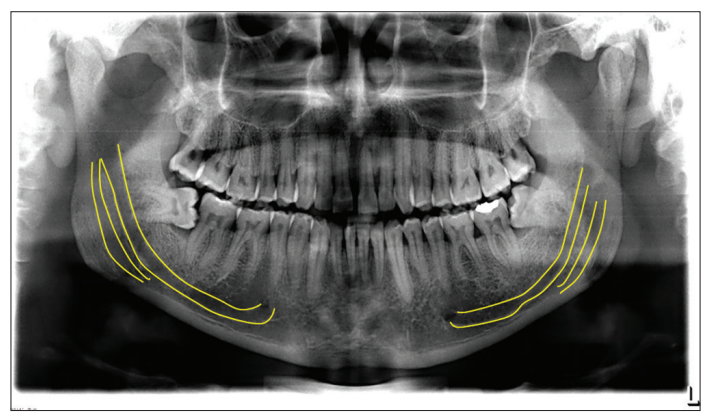

FIGURE 2. Class B - mesial direction.

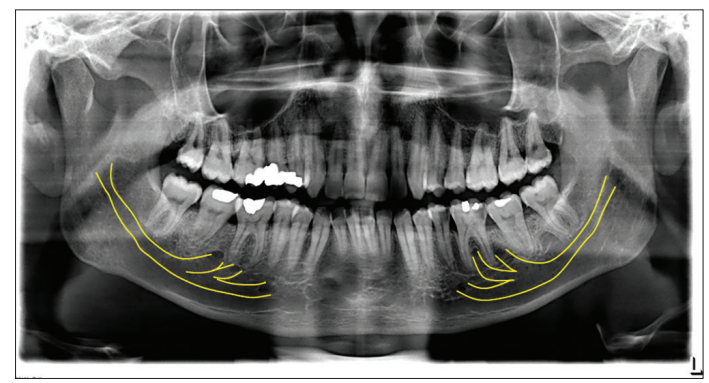

FIGURE 3. Class $\mathrm{C}$ - alveolar direction.

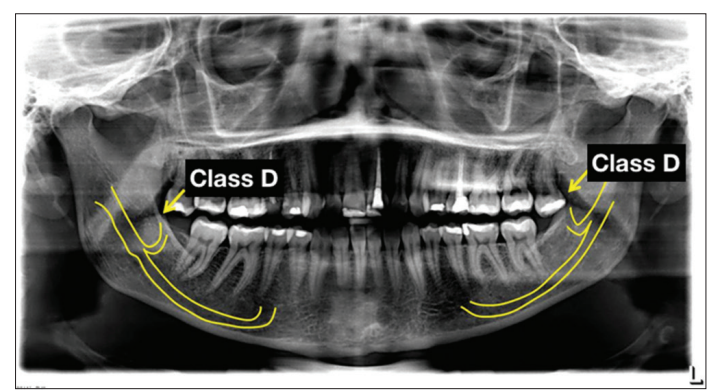

FIGURE 4. Class D - retromolar direction.

The evaluation of classification and frequency of anatomical alterations of the mandibular canal in the radiographs, as well as the identification of gender, age, and the affected side was analyzed by percentage frequency. Statistical analysis was described as absolute and relative frequencies, according to participants' gender and location (right unilateral, left unilateral, and bilateral). At the same time, associations between bifid mandibular canals and gender or location were investigated by Fisher's exact test and Chi-square tests, respectively.

The trajectory classification of the bifid mandibular canals was also submitted to descriptive approaches through frequencies. Statistical calculations were performed using SPSS 20 programs (SPSS INC., Chicago, IL, USA) and a significance level of $5 \%$ (0.05) was adopted.

\section{RESULTS}

In the 500 panoramic radiographs analyzed, 470 (94.0\%) presented single mandibular canals, while in the others, the presence of bifid mandibular canals was found, indicating that the prevalence rate of this condition in the sample of this study was $6.0 \%$.

The mean age between both genders with bifid mandibular canal was 31.5 years (Table 2). Regarding the absolute and relative frequencies of bifid mandibular canals according to location, the Chi-square test showed that the proportions of patients with bifid, bilateral, and unilateral canals, only on the left side, were significantly higher than the proportion of individuals with exclusively right bifid canals (Table 3).

In the 30 patients, that is, 18 males and 12 females, with the presence of bifid mandibular canals, these added 39 accessory conduits. In 17 of these (43.6\%), the direction was to mesial or anterior (Class B), while in another $13(33.3 \%)$, the trajectory was retromolar (Class D) (Table 4).

TABLE 2. Absolute (n) and relative (\%) frequencies of bifid mandibular canals on panoramic radiographs by gender

\begin{tabular}{lcccc}
\hline Gender & \multicolumn{2}{c}{ Bifid mandibular canals } & Total (\%) & p-value \\
\cline { 2 - 3 } & Present (\%) & Absent (\%) & & \\
\hline Male & $18(8.7)$ & $189(91.3)$ & $207(41.4)$ & \\
Female & $12(4.1)$ & $281(95.9)$ & $293(58.6)$ & 0.036 \\
Total & $30(6.0)$ & $470(94.0)$ & $500(100.0)$ & \\
\hline
\end{tabular}

*The $p$-value results from the application of Fisher's exact test 
In the absolute and relative frequencies of mandibular canals, according to classification and gender, in 18 male patients, Class B and Class D were the most prevalent (38.9\%) (Table 5).

\section{DISCUSSION}

This type of study seeks a detailed description of a number of changes, reporting in-depth the characteristics of interest that may suggest etiological hypotheses and represent an important interface between clinic and epidemiology referring to anatomical variations of the mandibular canal (5).

According to Kuribayashi et al. (6), the anatomical variations of the mandibular canal can be identified on panoramic radiographs (7). In another study, the

TABLE 3. Absolute (n) and relative (\%) frequencies of unilateral and bilateral bifid mandibular canals in panoramic radiographs, according to gender and affected side

\begin{tabular}{lccllll}
\hline \multirow{2}{*}{ Gender } & \multicolumn{2}{c}{ Unilateral } & & Bilateral & Total (\%) & p-value \\
\cline { 2 - 3 } & Right (\%) & Left (\%) & & Both (\%) & & \\
\hline Male & $1(5.6)$ & $13(72.2)$ & & $4(22.2)$ & $18(60.0)$ & 0.0065 \\
Female & $5(41.6)$ & $2(16.8)$ & & $5(41.6)$ & $12(40.0)$ & \\
Total & $6(20.0)$ & $15(50.0)$ & & $9(30.0)$ & $30(100.0)$ & \\
\hline
\end{tabular}

${ }^{*}$ The $p$-value results from the application of Pearson's Chisquare test. Statistically significant at $p<0.05$

TABLE 4. Absolute (n) and relative (\%) frequencies of unilateral and bilateral bifid mandibular canal accessory conduits in panoramic radiographs

\begin{tabular}{lcccc}
\hline CMBs & \multicolumn{2}{c}{ Unilateral } & Bilateral & Total (\%) \\
\cline { 2 - 3 } Classification & Right (\%) & Left (\%) & $(\%)$ & \\
\hline Class A & $0(0.0)$ & $0(0.0)$ & $0(0.0)$ & $0(0.0)$ \\
Class B & $4(23.5)$ & $5(29.4)$ & $8(47.1)$ & $17(43.6)$ \\
Class C & $0(0.0)$ & $3(33.3)$ & $6(66.7)$ & $9(23.1)$ \\
Class D & $2(15.4)$ & $7(53.8)$ & $4(30.8)$ & $13(33.3)$ \\
Total & $6(15.3)$ & 15 & $18(46.2)$ & $39(100.0)$ \\
& & $(38.5)$ & & \\
\hline
\end{tabular}

authors advocated the use of panoramic radiography to detect changes in the mandibular canal and stated that panoramic radiography is the exam of choice in the initial planning of dental patients, due to low doses of ionizing radiation, low cost, and allows a holistic evaluation of the maxillomandibular complex.

Langlais et al. (8) suggested the classification of bifid mandibular canals into four types: Type I (unilateral or bilateral bifurcation extending to the third molar region), Type II (unilateral or bilateral bifurcation extending along the main canal, joining the branch later), Type III (a combination of the first two classifications), and Type IV (two canals from two distinct holes that join to form a single mandibular canal).

Nortjé et al. (9), classified the variations of the mandibular canal anatomy in four different configurations: Two canals originating from a single mandibular foramen, Type 1; duplication or division of canals being one superior that goes toward the second or third molar, Type 2; duplicate canals starting from two distinct foramina and joining to form a single canal in the molar region of the body of the mandible, Type 3; and other variations, including duplication or division of the canal, apparent partial or complete absence of the canal or lack of symmetry, Type 4.

In our study, more complete classification was suggested that took into account other directions of the bifid canal, not contemplated by previous classifications, and that could correlate the anatomical changes of the mandibular canal with clinical and surgical practice, Class A (lower sense), Class B (mesial or anterior), Class C (alveolar), and Class $\mathrm{D}$ (retromolar). Therefore, the importance of this study is ratified.

Panoramic radiography is an initial image exam for planning implants in the posterior region of the mandible, although this presents limitations for the evaluation of

TABLE 5. Absolute ( $\mathrm{n}$ ) and relative (\%) frequencies of bifid mandibular canals on panoramic radiographs, by classification and gender.

\begin{tabular}{|c|c|c|c|c|c|}
\hline \multirow[t]{2}{*}{ Gender } & \multicolumn{4}{|c|}{ Classification } & \multirow[t]{2}{*}{ Total } \\
\hline & Class A & Class B & Class $\mathrm{C}$ & Class D & \\
\hline Male & $0(0,0 \%)$ & $7(38,9 \%)$ & $4(22,2 \%)$ & $7(38,9 \%)$ & $18(60,0 \%)$ \\
\hline Female & $0(0,0 \%)$ & $6(50,0 \%)$ & $2(16,7 \%)$ & $4(33,3 \%)$ & $12(40,0 \%)$ \\
\hline Total & $0(0,0 \%)$ & $13(43,6 \%)$ & $6(20 \%)$ & $11(36,4 \%)$ & $30(100,0 \%)$ \\
\hline
\end{tabular}


anatomical variations. Therefore, according to Freitas et al. (10), the exam of choice to assess such changes is cone-beam computed tomography.

Regarding the affected side, in this study, it was observed that the right side $(20.0 \%)$ was less affected than the left side $(50.0 \%)$ and $30 \%$ were bilateral. Data disagreeing with the studies Rossi et al. (4) and Freitas et al. (2), which found a higher prevalence on the right side, with a percentage ranging from 25.2 to $32.2 \%$ of the cases. Regarding both sides, in this study, $30.0 \%$ of bilateral bifid canals were observed, in agreement with the study by Freitas et al. (10) and Rossi et al. (4), finding the bilateral prevalence of the bifid mandibular canal with a percentage ranging from $25.0 \%$ to $43.3 \%$ of cases.

Sanchis et al. (11) and Nortjé et al. (9) reported a higher prevalence of bifid mandibular canals among females. While in the present study, the presence of bifid mandibular canal is more prevalent in male individuals, $8.7 \%$. One study (12) revealed a higher rate of the bifid mandibular canal on the right side of male patients (66.67\%), disagreeing with the results of our study, which shows a higher incidence of the left bifid mandibular canal $(72.2 \%)$, and female agreement in our study with $41.6 \%$ of the bifid mandibular canal prevailed on the right. However, some authors have not mentioned a higher incidence of gender in previous studies (13-15).

In our study, the images were classified as $43.6 \%$ for Class B (mesial or anterior feeling), 23.1\% for Class C (alveolar sense), and 33.3\% for Class D (retromolar sense). Freitas et al. (15), in their study, showed a $39.1 \%$ prevalence of retromolar canals, corroborating with this study.

In the present study, Type B (mesial or anterior feeling) was the most prevalent mandibular canal bifurcation (43.6\%), followed by Class D (retromolar direction), which occurred in $33.3 \%$. Freitas et al. (15) found a prevalence of $39.1 \%$ of bifid retromolar canals in their study. These data converge with our work. Less frequently, $23.1 \%$ of cases were classified as Class C (alveolar direction). Class A (lower direction) was not found in any of the 30 cases of the fork. Studies were not found classifying the variations of the mandibular canal concerning panoramic radiographs, thus confirming the importance of this study.
Classes B and C ducts presented the highest bilateral frequency, respectively, $47.1 \%$ and $66.7 \%$, followed by the left side, ranging from $29.4 \%$ to $33.3 \%$ and right from $15.4 \%$ to $23.5 \%$. Class D presented more frequently unilaterally on the left side $(53.8 \%), 15.4 \%$ on the right side, and $30.8 \%$ bilateral. Some authors $(16,17)$ showed a higher incidence on the left side, confirming the results of our study. Moreover, other studies found a higher prevalence on the right side $(18,19)$. Furthermore, some authors did not find a preference for the affected side in their studies $(20,21)$.

Regarding the frequency of bifid mandibular canal, according to classification and gender, Type B presented $50.0 \%$ of female patients, D 33.3\%, and C $16.7 \%$. In a male, Classes B and D had a similar frequency of $38.9 \%$ among themselves and C $22.2 \%$. Literature was not found to relate the frequencies of classification according to gender, confirming the importance of this research.

According to Perin et al. (22), a large number of dental surgeons do not know well about the morphological variations of the mandibular canal, and the presence of these variations when not previously identified causes several clinical implications, including nerve damage, such as paresthesia, hyperesthesia, bleeding, and lower efficiency in anesthetic technique.

According to Neves et al. (3), the dentist should recognize the possible anatomical variations of the mandibular canal while performing surgical or anesthetic techniques to reduce the risk of failure. For Orhan et al. (23), knowledge of the anatomy of this canal is essential for successful dental interventions and regional mandibular anesthesia, as well as dental implant placement and jaw surgery.

For Patriota (24), knowledge of the anatomy of the mandibular canal and its anatomical variations is essential for the planning of successful surgical procedures in the region. Lack of knowledge can lead to the failure of the conventional anesthetic technique, as well as intermittent bleeding during surgery, often leading the dentist to abort the procedure.

According to Kuribayashi et al. (6), in panoramic radiographs, anatomical variations of the mandibular canal can be identified. However, when more accurate information about the path of this channel is needed, the most appropriate exam is computed tomography. 
Naitoh et al. (25) performed a study comparing panoramic radiography with $\mathrm{CBCT}$ and were able to visualize bifid mandibular canals and accessory foramen in $48.6 \%$ of the cases, in which no changes were observed in panoramic radiographic images.

Freitas et al. (2) analyzed 300 CBCT images, in which they found $30.0 \%$ with anatomical variations of the bifid mandibular canals. Thus, panoramic radiography is the routine examination of dentists and is valid for the initial diagnosis of variations in the anatomy of the mandibular canal. However, whenever duplication of the mandibular canal is suspected, a conical beam tomographic examination should be ordered to confirm the diagnosis.

\section{CONCLUSIONS}

Based on the results obtained in this study, a prevalence of $6 \%$ of bifid mandibular canals was found. Being more prevalent in men, unilaterally, on the left side and the most frequent classification was Class B, followed by Class D.

\section{REFERENCES}

1. Freitas $G B$, de Silva AF, Junior LR, Junqueira JL. Prevalence and classification of bifid mandibular canals in CBCT examinations in different facial types. Rev Odontol UNESP 2018;47(2):85-91.

https://doi.org/10.1590/1807-2577.10617.

2. Freitas $G B$, de Silva $A F$, Morais $L A$, Silva $M B$, Silva $T C$, Júnior $L R$. Incidence and classification of bifid mandibular canals using cone beam computed tomography. Braz J Oral Sci 2015;14(4):294-8.

https://doi.org/10.1590/1677-3225v14n4a08.

3. Neves FS, Rodrigues V, Burgos V, Oliveira C, Campos PS, CrusoéRebello I. Anatomical variations of the mandibular canal observed in panoramic radiographs: Case reports. Int J Dent 2009;8(1):45-9.

4. Rossi PM, Brücker MR, Rockenbach Ml. Bifid mandibular canals: Panoramic radiographic analysis. Rev Ciênc Med 2009;18(2):99-104.

5. Antunes JL, Peres MA, Junior OC. Community Dent Oral Epidemiol. Rio de Janeiro, Portuguese: Guanabara Koogan; 2006.

6. Kuribayashi A, Watanabe H, Imaizumi A, Tantanapornkul W, Katakami K, Kurabayashi T. Bifid mandibular canals: Cone beam computed tomography evaluation. Dentomaxillofac Radiol 2010;39:235-9.

https://doi.org/10.1259/dmfr/66254780.

7. Chivarquer I, Chiavarquer LW, Saddy MS, Hayek JE. Implantodontics imaging diagnosis. In: Lubiana NF, editor. Prodonto Implante. Porto Alegre: Artmed/Panamericana 2007;

8. Langlais RP, Broadus R, Glass BJ. Bifid mandibular canal in panoramic radiographs. J Am Dental Assoc 1985;110(6):923-6. https://doi.org/10.14219/jada.archive.1985.0033.

9. Nortjé CJ, Farman AG, Grotepas FW. Variations in the normal anatomy of the inferior dental mandibular canal: A retrospective study of panoramic radiographs from 3612 routine dental patients. $\mathrm{Br} \mathrm{J}$ Oral Surg 1978;15:55-63. https://doi.org/10.1016/0007-117x(77)90008-7.

10. Freitas GB, Silva AF, Morais LA, Silva MB, Silva TC, Manhães LR Jr. Incidence and classification of bifid mandibular canals using cone beam computed tomography. Braz J Oral 2015;14(4):8.

https://doi.org/10.1590/1677-3225v14n4a08.

11. Sanchis JM, Peñarrocha M, Soler F. Bifid mandibular canal. Am J Oral Maxillofac Surg 2003;61:422-4.

https://doi.org/10.1053/joms.2003.50004.

12. Carvalho MF. Evaluation of the Prevalence of Bifid Mandibular Canals in Cone-Beam Computed Tomography, Thesis. São Paulo, Brazil: Faculdade de Odontologia de São José dos Campos. Unesp Univ Estadual Paulista; 2012. https://doi.org/10.24873/j.rpemd.2019.11.464.

13. Schejtman R, Devoto FC, Arias NH. The origin and distribution of the elements of the human mandibular retromolar canal. Arch Oral Biol 1967;12(11):1261-7. https://doi.org/10.1016/0003-9969(67)90127-6.

14. Kim MS, Yoon SJ, Park HW, Kang JH, Yang SY, Moon YH, et al. A false presence of bifid mandibular canals in panoramic radiographs. Dentomaxillofac Radiol 2011;40(7):434-8.

https://doi.org/10.1259/dmfr/87414410.

15. Freitas GB, Silva AC, Júnior LR. The prevalence of mandibular retromolar canals on cone beam computed tomography and its clinical repercussions. Rev Odontol UNESP 2017;46(3):231-6.

https://doi.org/10.1590/1807-2577.00117.

16. Priya R, Manjunath KY, Balasubramanyam V. Retromolar foramen. Indian J Dent Res 2005;16:15-6.

17. Motta-Junior J, Ferreira ML, Matheus RA, Stabile GA. Retromolar foramen: Its clinical repercussion and evaluation of 35 dry jaws. Rev Odontol UNESP 2012;41(3):164-8.

18. Narayana K, Nayak UA, Ahmed WN, Bhat JG, Devaiah BA. The retromolar foramen and canal in South Indian dry mandibles. Eur J Anat 2002;6(3):141-6.

19. Han SS, Hwang YS, Cone beam CT findings of retromolar canals in a Koren population. Surg Radiol Anat 2014;36(9):871-6.

https://doi.org/10.1007/s00276-014-1262-1.

20. Patil S, Matsuda Y, Nakajima K, Araki K, Okano T. Retromolar canals as observed on cone-beam computed tomography: Their incidence, course, and characteristics. Oral Surg Oral Med Oral Pathol Oral Radiol 2013;115(5):692-9.

https://doi.org/10.1016/j.0000.2013.02.012

21. Muinelo-Lorenzo J, Suárez-Quintanilha JA, Fernández-Alonso $A$, Marsillas-Rascado S, Suárez-Cunqueiro MM. Descriptive study of the bifid mandibular canals and retromolar foramina: Cone beam CT VS panoramic radiography. Dentomaxillofac Radiol 2014;43(5):20140090.

https://doi.org/10.1259/dmfr.20140090.

22. Perin CP, Suzuki AM, Ferandes A, Westphalen FH, Schussel JL. Importance of the anatomical variations of the mandibular canals and their clinical implications. JBC J Bras Clin Odontol Integr 2004;44:144-6.

23. Orhan K, Aksoy S, Bicenoglu B, Sakul BU, Paksoy CS. Evaluation of bifid mandibular canals with cone beam computed tomography in a Turkish adult population: A retrospective study. Surg Radiol Anat 2011;33(6):501-7. https://doi.org/10.1007/s00276-010-0761-y.

24. Patriota IG. Evaluation of the Prevalence of Retromolar Canal in Different Facial Patterns in CBCT, Thesis. Paraiba, Brazil: Faculdade Integrada de Patos; 2017.

25. Naitoh M, Yoshida K, Nakahara K, Gotoh K, Ariji E. Demonstration of the accessory mental foramen using rotational panoramic radiography compared with cone-beam computed tomography. Clin Oral Impl Res 2011;22(12):1415-9.

https://doi.org/10.1111/j.1600-0501.2010.02116.x. 